\title{
Remarks on Culture Injection of Second Language Education
}

\author{
Liu Wen \\ Information Science and Technology Institute, \\ Zhengzhou, China \\ liuwenpaper@126.com
}

\author{
Gao Mingxia \\ Information Science and Technology Institute, \\ Zhengzhou, China
}

\begin{abstract}
Cultural injection of the second foreign language teaching is an important content; it can help students in the humanities aspects and communication skills, and also enables students to understand the target language. In this paper, we describe the significance of the cultural injection, and then introducing the implementation approaches.
\end{abstract}

Keywords-language education; culture injection; literature; custom

\section{INTRODUCTION}

The teaching of the culture is one of the teaching target of language itself. We cannot truly master the language until we have also mastered the culture when we are learning language. The main goal of language is to build so-called communication ability. Among the "communication ability", language ability is a foundation but not all of it. More and more persons have already reached common. We must understand that language ability refers to each other in social life, understand that culture knowledge is an important respect which makes up communication ability, is the important content of courses which reaches the teaching goal of language.

The relationship between language education and culture has been attracting many researchers' interests. The culture could be realized as a dynamic and ever changing one[1,2]. It is connected with beliefs and knowledge and defined as a set of attitudes based on our responses and beliefs.

Better culture injection helps language teaching[3,4,5]. Research shows that the way learners respond to culture of the target language affects their attitude towards the language. And learning foreign language essentially involves learning its culture, the positive effect of using culture on learners' cognitive attitude is that the teaching of culture in language instruction results in positive view to the target language.

For several decades, the dominant method in second language teaching has been the 'communicative approach', an approach which has tended to underestimate the cultural dimensions of language use. Research indicates that a language course concerned with culture will primarily focus on people rather than on language in isolation, and will help learners to get cultural skills. Since the "culture" concept is really vast, there exist massive works for us to study[6]. In this paper, we will discuss how to inject the culture part in the language cause.

\section{PRactical Situation in the Language CAUSE}

A cultural can never be taught in a pure language class. People came to a common ground that language cause should concentrate on cultivating the students' abilities of crosscultural communication and their awareness of culture. In cross-cultural communication, people are required with not only the knowledge of words and grammar, but also the understanding of the culture carried in the target language. This may reduce the possibility of misunderstanding caused by cultural barriers. So it is important to cultivate the students' sensitivity over the target language in English classroom.

Sometimes, teaching of culture in the language classroom also receives negative responses. And most of the teachers argue against the teaching of target culture in language classroom and they believe that the language learners are more motivated when they compare target language with their owns. And it also seems that learners are more likely to adopt positive attitude towards the target language if the target culture is close to their own culture. A very typical example is: Chinese people respect their teachers, so the teacher becomes a honorific. And western people only treat the teacher as a simple job. Therefore, if someone says because of respect for the "teacher", it will be hardly understood by a westerner. This will also bring some shock to the learners.

Another reality is, in the teaching process of the second language, due to limited hours, teachers tend to focus more on introducing the knowledge of the language, instead of the cultivation of cultural knowledge. The downside to this action is that students tend to be disturbed native culture, making it difficult to properly use language in different situations, but also limit students' intercultural communicative ability.

\section{How to AdD The CUlTuRe PART IN THE SECOND LANGUAGE CAUSE?}

\section{A. Adding Culture Part through Literature in Second Language Teaching}

There are many aspects of a culture that may appear in literary texts emanating from or set against the background of 
that culture. The advantages and disadvantages of learning culture through literature have however been the subject of debate. Among those who see a role for literary texts in promoting cultural awareness. Some researchers suggest that the practical educational utility of literary texts is that they can vividly illustrate aspects of an entire society, which means, appreciation of others' viewpoints is one of the things students are in education to learn, and literature may be able to support or facilitate such learning.

In the cause of the literature, a very typical example is: Chinese people tend to believe that the dragon is a symbol of authority and good fortune, while western dragons are considered cruel raging monster; and if Chinese people say "dog", in most of time, they say with derogatory sense, and hence Chinese have the "goujitiaoqiang(cornered)", "langxingoufei(ungrateful)" and other phrases. Westerners admire the brave and loyal dog, praise is also not uncommon for dogs, and the dogs were compared. This phenomenon can be found almost everywhere in literature. In the literature causes, teachers should pay attention on these phenomena.

\section{B. Compare with Native Culture}

It is hard to deny that with the world being smaller and smaller, the world's culture is getting closer and closer now. So, there are fewer cultural shocks, and this seems beneficial to our cause.

But there still some differences between east and west, because of the different culture background.

Chinese culture possesses a wide knowledge of ancient things. Such as the Chinese characters, traditional Chinese art, Chinese festivals and so on. This Chinese tradition all have a long history and the development of culture is very far reaching. Likewise, western culture has much unique features and it is entirely different with Chinese style especially, the difference of custom, for example, greeting customs: In most western countries, people hug or kiss when they say the first hello to others while Chinese shake hands with each other. And Japanese people bow all the time. In table customs, utensils are different. Chinese are used to use to use the chopsticks to eat. Some westerners use folks, knives and spoons and some like using their hands, like Indian people. Because of using chopsticks, when Chinese people having rice or soup, it's likely for us to hold up bowls. But this habit is considered rude in the Western countries. But we cannot deny any of the remarks, instead, we should get to learn how to coordinate the different cultures on so called Table manner. The etiquette in the West requests that when eating, bowls and plates cannot leave the tables. Food should be cut by knives to fit into the mouths. Of course your mouth cannot touch the plates or bowls. So the regular process is like this. You cut your steak on the plate with fork and knife, send the meat cube into the mouth with fork and nothing will be returned back but the fork alone.

\section{Introducing the Custom of the Target Language}

Custom refers to abide by a common cultural background between the members of the rules and habits. Language differences between Chinese and Western culture in the custom of the two peoples reflected vividly, we should notice that customs and everyday communication are closely related, thus introducing custom in western countries can both increase students' ability to everyday communication, and enhancing the interests of students in learning a second language. Thus the second language teaching content should be appropriate to add the daily communication practices, allowing students to understand and use language better.

In my course, I intentionally set some simulation scenarios of international affairs, let students to focus on a hot international issues currently taking place, let them gather information and allow the parties to debate the simulation.

In the debating simulation, students can build a preliminary understanding of cultural backgrounds and the way of thinking, and this simulation can also help the students to use their language ability, which seems a little bit lack in the classroom.

\section{Making Good Use of the Students' Language Background}

Most Western languages belong to the same language (such as English and French to belong to the Indo-European), in vocabulary between languages with a language there are many things in common, according to statistics, and English anthropomorphic meaning or near tantamount to account for about three-quarters of French words meaning French words total. Meanwhile, western countries are inextricably linked in history, ways of thinking and the cultural background is very similar to each other. Therefore, in the teaching process, if a student has a language background, the use of contrast teaching methods allow students to acquire the target language in contrast to the association process, which often can achieve a multiplier effect, this method will also lead students from a new language to a more intimate and familiar one, which greatly stimulate their interest in learning.

In my classroom, I have done a test, 120 just contact French, and have English-educated background students were randomly assigned to two classes, A and B, and in the A class, I did not deliberately use and comparison of English, but simply let them learn the inherent knowledge of French; while in class B, I intentionally contrasting ways to teach French, from time to time out of the linguistic phenomenon and vocabulary, and English were compared. A month later, I received the following test results(see Table.1): TABLE I.
System)

\begin{tabular}{|l|l|l|}
\hline & Class A & Class B \\
\hline Average motivation & 70 & 82 \\
\hline Average test scores & 76 & 79 \\
\hline Course difficulty scoring & 79 & 60 \\
\hline
\end{tabular}

From the Table, Class B performance indicators are more positive, and in the assessment of the difficulty of the course, Class B exceeds Class A obviously. This shows that using 
comparative approach will be more effective, and can significantly reduce the fear of a second language learners.

\section{IV.CONCLUSION}

Since there is a very close relationship between language and culture, to learn a foreign language, you must understand the cultural connotations behind the language. Different civilizations created a different culture, and Chinese and Western cultures there are significant differences in all aspects Therefore, in the process of teaching a second language, the culture is an important part of the import indispensable. This enables students to understand humanities and communication skills, help them in getting the knowledge of the language.

We need to pay full attention to the cultural injection role in teaching, more innovation in approach and more exploration in practice to improve the quality of teaching.

\section{REFERENCES}

[1] Ariffin. S. 2006. Culture in EFL teaching: issues and solutions. TESL Working Paper Series 4(1):75-78.

[2] Hofstede G . 1997. Cultures and organizations: softwares of the mind. McGraw Hill, New York 34(5):82-95.

[3] Shafaei. A, Nejati. M. 2008. Global practices of language teaching. In: Proceedings of the 2008 international online language conference. Universal-Publishers 36(31):73-84.

[4] Sava.I. 1998. Art education in a multicultural context. A multiartistic project for the research and development of ethnic multicultural practices in an elementary school in Helsinki. Helsinki: City of Helsinki, Education Department. Publication Series.

[5] Alptekin, Margaret. 1984. The question of culture: EFL teaching in nonEnglish-speaking countries. ELT journal 38.1 : 14-20.

[6] Duff, P. A., \& Uchida, Y. 1997. The negotiation of teachers' sociocultural identities and practices in postsecondary EFL classrooms. Tesol Quarterly,31(3), 451-486. 